\title{
PENGARUH TERAPI TERTAWA TERHADAP TINGKAT KECEMASAN PADA LANJUT USIA DI UPTD GRIYA WERDHA SURABAYA
}

\author{
Farida Umamah*, Nazula Mufarrihah** \\ Fakultas Keperawatan dan Kebidanan \\ Universitas Nahdlatul Ulama Surabaya, Jln. Smea 57 Surabaya \\ Email: umamahfarida@unusa.ac.id
}

\begin{abstract}
The influence of an aging process experienced by elderly led to various problems such as physically, mental, and social economic. One of the psychological problems experienced by the elderly is anxiety. The purpose of this study is to find the influence of laugh therapy at the level of anxiety on elderly at the UPTD Griya Werdha Surabaya. This research using pre-experimental design by the approach one group pra-post test design, the amount of the sample 33 elderly aged 60-74 years, uses probability sampling by the simple random sampling technique. The independent variable is laugh therapy and the dependent variable is the extent of anxiety on elderly. Uses a DASS 42 questionnaire 42 (Depression Anxiety Stress Scale), analyzed by Wilcoxon sign test. The research results show before it was given laugh therapy most of 17 respondents $(51,5 \%)$ is having moderate anxiety and after having given laugh therapy obtained almost entirely 30 respondents ( $90,9 \%)$ is having mild anxiety. The results of the analysis $\rho=0,000$ where $\rho=0,000$ means $h 0$ rejected. It means there are the influence of laugh therapy on the level of anxiety on elderly at the UPTD Griya Werdha Surabaya. The conclusions from the study, laugh therapy is able to reduce the anxiety on the elderly. Hopefully the nurse will continue the laugh therapy at UPTD Griya Werdha Surabaya, so that elderly motivated to do this activity regularly and gather.
\end{abstract}

Keyword: Laughing Therapy, Level of Anxiety, Elderly

\begin{abstract}
Abstrak : Pengaruh proses penuaan yang dialami oleh lansia menimbulkan berbagai masalah baik secara fisik, mental, maupun sosial ekonomi. Salah satu masalah psikologis yang dialami lansia adalah terjadinya kecemasan. Tujuan dari penelitian ini adalah untuk mengetahui pengaruh terapi tertawa terhadap tingkat kecemasan pada lanjut usia di UPTD Griya Werdha Surabaya. Penelitian ini menggunakan desain pre-eksperimental dengan pendekatan one group pra-post test design dengan besar sampel 33 lansia yang berusia 60-74 tahun, menggunakan probability sampling dengan teknik simple random sampling. Variabel independen adalah terapi tertawa dan variabel dependen adalah tingkat kecemasan pada lanjut usia. Menggunakan kuesioner DASS 42 (Depression Anxiety Stress Scale), dianalisis menggunakan uji Wilcoxon sign test. Hasil penelitian menunjukkan sebelum diberikan terapi tertawa sebagian besar 17 responden $(51,5 \%)$ mengalami kecemasan sedang dan setelah diberikan terapi tertawa didapatkan hampir seluruhnya 30 responden $(90,9 \%)$ mengalami kecemasan ringan. Hasil analisis $\rho=0,000$ dimana $\rho<0,05$ berarti $\mathrm{H}_{0}$ ditolak artinya ada pengaruh terapi tertawa terhadap tingkat kecemasan pada lanjut usia di UPTD Griya Werdha Surabaya. Simpulan dari penelitian ini bahwa terapi tertawa mampu menurunkan tingkat kecemasan pada lanjut usia. Diharapkan perawat bisa melanjutkan kegiatan terapi tertawa di UPTD Griya Werdha Surabaya, sehingga lansia termotivasi untuk melakukan hal ini secara rutin dan berkelompok.
\end{abstract}

Kata Kunci : : Terapi Tertawa,Tingkat Kecemasan, Lansia

\section{PENDAHULUAN}

Penuaan adalah suatu proses alami yang tidak dapat dihindari, berjalan terus-menerus, dan berkesinambungan. yang menyebabkan perubahan anatomi, fisiologis, dan biokimia pada tubuh sehingga akan mempengaruhi fungsi dan kemampuan tubuh secara keseluruhan (Maryam, R S., 2008). Proses penuaan akan menimbulkan berbagai masalah baik secara fisik, 
mental, maupun sosial ekonomi. Salah satu gangguan mental pada lansia adalah kecemasan. Kurangnya waktunya keluarga untuk memberi perhatian, tidak dirawat keluarga, ketidakcocokan dengan keluarga atau keluarga sangat sibuk dengan kegiatannya sehingga lansia akan ditempatkan di panti. Keadaan ini cenderung berpotensi menimbulkan masalah kesehatan, secara umum maupun kesehatan jiwa. Keputusan keluarga menempatkan lanjut usia di panti belum tentu diterima oleh lansia tersebut. Lansia dipanti akan mengalami perubahan sosial dalam kehidupan sehari-hari lansia takut akan kesepian, sadar akan kematian, tidak ada yang perduli, memperhatikan, kurang kasih sayang dari keluarga, kekosongan, rasa tidak dibutuhkan lagi, keterasingan dari lingkungan, ketidakberdayaan, ketergantungan, kurang percaya diri, serta kurangnya dukungan dari anggota keluarga, perubahan tersebut akan menimbulkan masalah kecemasan (Maryam, R. S., 2008). Kecemasan yang dapat menghilangkan kebahagiaan, hasrat, harapan, ketenangan pikiran dan kemampuan untuk merasakan ketenangan hidup, hubungan yang bersahabat dan bahkan menghilangkan keinginan menikmati kehidupan sehari-hari. Kecemasan yang berkepanjangan tidak menutup kemungkinan lansia akan mengalami keputusasaan.

Berdasarkan survey awal yang dilakukan peneliti pada bulan November 2016 di UPTD Griya Werdha Surabaya dengan melalui wawancara kepada 10 orang lansia, didapat 7 dari 10 orang menyatakan lebih suka menyendiri dari pada berkumpul dengan teman sebayanya, lansia juga menyatakan sulit tidur pada malam hari karena lansia merasa cemas dan takut apa yang akan terjadi dikemudian hari. Sedangkan 3 orang lansia menyatakan senang tinggal dipanti karena karena memiliki teman yang sebaya, ada yang membantu dalam kegiatan sehari-hari, tidak mengalami gangguan tidur pada malam hari dan tidak ada masalah yang dikhawatirkan.

Faktor-faktor yang mempengaruhi kecemasan pada lansia meliputi lingkungan atau sekitar tempat tinggal mempengaruhi cara berfikir individu tentang diri sendiri maupun orang lain, emosi yang ditekan, sebab-sebab fisik atau pikiran dan tubuh senantiasa saling berinteraksi dan dapat menyebabkan timbulnya kecemasan (Manurung, Nixson., 2016). Kecemasan pada lansia memliki gejala seperti, perasaan khawatir atau takut, mudah tersinggung, kecewa, gelisah, perasaan kehilangan, sulit tidur sepanjang malam, sering membayangkan hal-hal yang menakutkan dan rasa panik pada hal yang ringan, konflik-konflik yang ditekan dan berbagai masalah yang tidak terselesaikan akan menimbulkan kecemasan (Maryam, R.S., 2008). Permasalahan yang terjadi beralih menjadi perasaan khawatir, sehingga kerisauan mereka menjadi bertambah besar. Kekhawatiran yang mereka rasakan terus-menerus mengakibatkan mereka kurang efektif dalam menjalankan tugas sehari-hari, sehingga terjadi sesuatu yang salah pada diri mereka. Alasan apapun yang terjadi, jika individu mulai merasakan kecemasan, maka mereka tidak dapat mengendalikan perasaan itu (Halgin, R.P., Whitbourne, S.K., 2010). 
Penatalaksanaan untuk mengurangi tingkat kecemasan pada lanjut usia dilakukan dengan terapi farmakologi dan non-farmakologi, dimana terapi farmakologi dengan diberikannya obat anti kecemasan nonbenzodiazepine, seperti buspiron (Buspar) dan berbagai antidepresan juga digunakan (Isaacs, Aan., 2005). Dan non-farmakologi meliputi distraksi dan relaksasi, dimana distraksi merupakan metode untuk menghilangkan kecemasan dengan cara mengalihkan perhatian pada hal-hal lain sehingga akan lupa terhadap cemas yang dialami (Potter, Patricia A \& Perry Anne G., 2005). Salah satu distraksi yang efektif adalah dengan memberikan terapi tertawa. Terapi tertawa adalah suatu terapi untuk mencapai kegembiraan di dalam hati yang dikeluarkan melalui mulut dalam bentuk suara tawa, atau senyuman yang menghiasi wajah, perasaan hati yang lepas dan bergembira, dada yang lapang, peredaran darah yang lancar sehingga dapat mencegah penyakit dan memelihara kesehatan (Setyoadi, Kushariyadi., 2011). Terapi ini dapat dilakukan dengan cara memberikan stimulus humor dan sengaja tertawa. Tertawa juga dapat membantu membentuk pola pikir positif sehingga seseorang akan berpikir dengan cara yang lebih positif. Tertawa merupakan cara yang paling baik dan paling ekonomis dalam melawan kecemasan dalam tertawa akan merelaksasikan otot-otot yang tegang, juga melebarkan pembuluh darah sehingga memperlancar aliran darah ke seluruh tubuh. Tertawa 5-10 menit bisa merangsang pengeluaran endorpine dan serotonin, yaitu sejenis morfin alami tubuh dan juga metanonin. Ketiga zat ini merupakan zat yang baik untuk otak sehingga bisa merasa lebih tenang (Ayu, A., 2010).

\section{METODE}

Desain penelitian menggunakan analitik dengan pedekatan pre eksperimental dengan pendekatan onegroup pra-post test design. Populasi pada penelitian ini adalah seluruh lansia yang mengalami kecemasan berusia 60-74 tahun di UPTD Griya Werdha Surabaya sebesar 36 orang dengan besar sampel 33 responden yang di ambil melalui probability sampling dengan teknik simple random sampling. Instrumen yang digunakan peneliti pada variabel independen adalah lembar observasi, lembar evaluasi dan dokumentasi. Untuk lembar observasi, evaluasi dan dokumentasi saat pelaksanaan terapi untuk mengetahui perkembangan lansia dalam dirinya. Sedangkan untuk variabel dependen instrumen pengumpulan data yang digunakan adalah lembar kuisioner yaitu kuisioner penilaian tingkat kecemasan DASS 42 (Depression Anxiety Stress Scale).

Data yang sudah terkumpul dilakukan coding atau dikoreksi melalui lembar observasi, kemudian dianalisa nilai tingkat kecemasan (pre) sebelum dan sesudah (post) dilakukan terapi tertawa pada satu kelompok dengan menggunakan uji statistik yaitu uji Wilcoxon Signed Rank Test dengan tingkat kemaknaan $\alpha=0,05$ yang dianalisis dengan menggunakan SPSS For Windows 18,0. Jika hasil uji statistik menunjukkan $\rho<0,05$ maka hipotesis penelitian $\left(\mathrm{H}_{\mathrm{o}}\right)$ ditolak yang berarti ada pengaruh terapi tertawa terhadap tingkat kecemasan pada lansia di UPTD Griya Werdha Surabaya. 
HASIL DAN PEMBAHASAN

\section{HASIL}

1.Data Umum

a. Karakteristik

berdasarkan jenis kelamin

Tabel 1 Distribusi frekuensi responden berdasarkan jenis kelamin pada terapi tertawa terhadap tingkat kecemasan pada lanjut usia di UPTD Griya Werdha Surabaya.

\begin{tabular}{lcc}
\hline Jenis Kelamin & $\begin{array}{c}\text { Frekuensi } \\
(\mathrm{n})\end{array}$ & $\begin{array}{c}\text { Persentase } \\
(\%)\end{array}$ \\
\hline Laki-laki & 11 & 33,3 \\
\hline Perempuan & 22 & 66,7 \\
\hline Jumlah & 33 & 100,0 \\
\hline Sumber : Data Primer Maret 2017
\end{tabular}

Sumber : Data Primer, Maret 2017

Berdasarkan table 1 menunjukkan bahwa dari 33 responden didapatkan sebagian besar 22 responden $(66,7 \%)$ memiliki jenis kelamin perempuan.

b. Distribusi responden berdasarkan usia

Tabel 2 Distribusi frekuensi responden berdasarkan usia pada terapi tertawa terhadap tingkat kecemasan pada lanjut usia di UPTD Griya Werdha Surabaya.

\begin{tabular}{lcc}
\hline Umur (tahun) & $\begin{array}{c}\text { Frekuensi } \\
(\mathrm{n})\end{array}$ & $\begin{array}{c}\text { Persentase } \\
(\%)\end{array}$ \\
\hline 60-74 tahun & 33 & 100.0 \\
\hline Jumlah & 33 & 100.0 \\
\hline Sumber : Data Primer, Maret 2017
\end{tabular}

Berdasarkan tabel 2 menunjukkan bahwa seluruh dari responden $(100 \%)$ memiliki umur 60-74 tahun.

1. Data Khusus

a. Karakteristik tingkat kecemasan pada lanjut usia sebelum diberikan terapi tertawa
Tabel 3 Distribusi

frekuensi

responden berdasarkan tingkat kecemasan pada lanjut usia sebelum diberikan terapi tertawa di UPTD Griya Werdha Surabaya.

\begin{tabular}{lcc}
\hline \multicolumn{1}{c}{$\begin{array}{c}\text { Tingkat } \\
\text { Kecemasan } \\
\text { Pre }\end{array}$} & $\begin{array}{c}\text { Frekuensi } \\
(\mathrm{n})\end{array}$ & $\begin{array}{c}\text { Persentase } \\
(\%)\end{array}$ \\
\hline $\begin{array}{l}\text { Kecemasan } \\
\text { ringan }\end{array}$ & 8 & 24,2 \\
\hline $\begin{array}{l}\text { Kecemasan } \\
\text { sedang }\end{array}$ & 17 & 51,5 \\
\hline $\begin{array}{l}\text { Kecemasan } \\
\text { berat }\end{array}$ & 8 & 24,2 \\
\hline Panik & 0 & 0 \\
\hline Jumlah & 33 & 100,0 \\
\hline Sumbr: Data Primer
\end{tabular}

Sumber : Data Primer, Maret 2017

Berdasarkan tabel 3 menunjukkan bahwa dari 33 responden, didapatkan sebagian besarresponden $(51,5 \%)$ mengalami kecemasan sedang.

b. Karakteristik tingkat kecemasan pada lanjut usia sesudah diberikan terapi tertawa

Tabel 4 Distribusi frekuensi responden berdasarkan tingkat kecemasan pada lanjut usia sesudah diberikan terapi tertawa di UPTD Griya Werdha Surabaya.

\begin{tabular}{lcc}
\hline \multicolumn{1}{c}{$\begin{array}{c}\text { Tingkat } \\
\text { Kecemasan } \\
\text { Post }\end{array}$} & $\begin{array}{c}\text { Frekuensi } \\
\text { (n) }\end{array}$ & $\begin{array}{c}\text { Persentase } \\
(\%)\end{array}$ \\
\hline $\begin{array}{l}\text { Kecemasan } \\
\text { ringan }\end{array}$ & 30 & 90,9 \\
\hline $\begin{array}{l}\text { Kecemasan } \\
\text { sedang }\end{array}$ & 3 & 9,1 \\
\hline $\begin{array}{l}\text { Kecemasan } \\
\text { berat }\end{array}$ & 0 & 0 \\
\hline Panik & 0 & 0 \\
\hline Jumlah & 33 & 100,0 \\
\hline Sumber : Data Primer,
\end{tabular}

Sumber : Data Primer, Maret 2017

Berdasarkan tabel 4 menunjukkan bahwa dari 33 responden, didapatkan hampir seluruhnya (90,9\%) mengalami kecemasan ringan. 
c. Pengaruh terapi tertawa terhadap tingkat kecemasan pada lanjut usia di UPTD Griya Werdha Surabaya
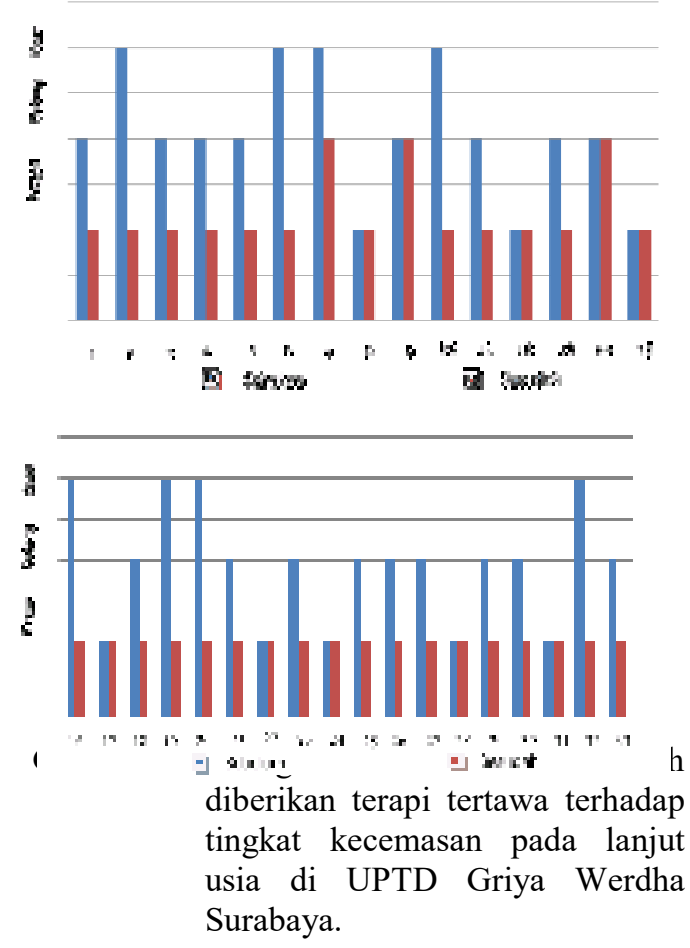

Berdasarkan gambar 5 didapatkan bahwa sebelum dan sesudah diberikan terapi tertawa menunjukkan sebagian besar responden $(70 \%)$ mengalami penurunan tingkat kecemasan, hampir setengah dari responden $(30 \%)$ menunjukkan tidak ada perubahan tingkat kecemasan sebelum dan sesudah diberikan terapi tertawa dan tidak ada satupun responden $(0 \%)$ yang mengalami peningkatan tingkat kecemasan setelah diberikan terapi tertawa.

Berdasarkan hasil uji statistic dengan menggunakan uji Wilcoxon Sign Rank Test sebelum dan sesudah diberikan terapi tertawa didapatkan nilai kemaknaan $\rho=0,000$ dimana $\rho<0,05$ yang berarti Ho ditolak yang artinya ada pengaruh terapi tertawa terhadap tingkat kecemasan pada lanjut usia di UPTD Griya Werdha Surabaya

\section{PEMBAHASAN}

1. Tingkat kecemasan pada lanjut usia sebelum diberikan terapi tertawa

Berdasarkan tabel 5.3

menunjukkan tingkat kecemasan pada lanjut usia di UPTD Griya Werdha Surabaya sebelum diberikan terapi tertawa, bahwa dari 33 responden sebagian besar $17(51,5 \%)$ responden mengalami kecemasan sedang.

Kecemasan sedang adalah seseorang dimana lahan persepsi terhadap masalah mulai menurun, lebih memfokuskan pada hal-hal penting saat itu dan mengesampingkan hal yang lain dengan gejala yang dirasakan adalah responden merasa cepat lelah, merasa khawatir jika memikirkan masalah, takut tanpa alasan yang jelas, dan seringkali mencemaskan terhadap sesuatu hal atau seseorang (Manurung Nixson, 2016). Perubahan-perubahan yang terjadi pada lansia akibat proses menua sering menimbulkan beberapa dampak bagi lansia diantaranya perubahan tingkah laku, sensitifitas emosional meningkat serta menimbulkan kecemasan. Sedangkan dari perubahan-perubahan yang timbul sebagai dampak proses menua, lansia dituntut untuk menyesuaikan diri secara emosional. Penyesuaian emosional terhadap penuaan pada dasarnya merupakan perluasan dari penyesuaian yang telah di lakukan individu terhadap perubahanperubahan dalam hidupnya (Darmojo dalam Kristanti, 2010). Berdasarkan teori diatas peneliti berpendapat bahwa kecemasan yang diderita lansia tersebut dikarenakan dari berbagai 
faktor kondisi fisik dan psikologis responden seiring dengan bejalannya proses penuaan berdampak pada terjadinya kecemasan, didukung dengan adanya hasil kuesioner yang mengatakan bahwa responden merasa cepat lelah, ketakutan tanpa alasan yang jelas, merasa khawatir jika memikirkan masalah, dan seringkali mencemaskan terhadap sesuatu hal atau seseorang.

2. Tingkat kecemasan pada lanjut usia sesudah diberikan terapi tertawa

Berdasarkan tabel 5.4 menunjukkan tingkat kecemasan pada lanjut usia di UPTD Griya Werdha Surabaya sesudah diberikan terapi tertawa, bahwa dari 33 responden hampir seluruhnya 30 responden $(90,9 \%)$ mengalami kecemasan ringan.

Kecemasan ringan berhubungan dengan ketegangan dalam kehidupan sehari-hari, kecemasan ini menyebabkan seseorang menjadi waspada dan meningkatkan lapang persepsinya. Mekanisme koping yang dimiliki oleh seseorang dengan kecemasan ringan memberi pengaruh positif bagi dirinya, sehingga tingkat kecemasan yang dialaminya hanya berada pada kecemasan tingkat ringan (Manurung Nixson, 2016). Lanjut usia yang sukses adalah meraka yang aktifdan banyak ikut serta dalam keguatan sosial. Lansia akan merasakan kepuasan bila dapat melakukan aktivitas dan mempertahankan aktivitas tersebut selama mungkin (Darmojo, 2010). Adanya perubahan yang signifikan menujukkan bahwa terapi tertawa yang dilakukan selama 4 kali dalam 4 hari secara berturut-turut memberikan dampak bagi lansia yang mengalami kecemasan. Respon kecemasan seseorang dapat terjadi berbagai perubahan akibat keadaan yang di alami oleh lansia dan dipengaruhi oleh berbagai faktor, dengan gejala yang sebelumnya responden merasa cepat lelah, merasa khawatir jika memikirkan masalah, takut tanpa alasan yang jelas, dan seringkali mencemaskan terhadap sesuatu hal atau seseorang.

3. Pengaruh terapi tertawa terhadap tingkat kecemasan pada lanjut usia di UPTD Griya Werdha Surabaya

Berdasarkan gambar 5.1 didapatkan bahwa sebelum dan sesudah diberikan terapi tertawa menunjukkan sebagian besar responden $(70 \%)$ mengalami penurunan tingkat kecemasan, hampir setengah dari responden $(30 \%)$ menunjukkan tidak ada perubahan tingkat kecemasan sebelum dan sesudah diberikan terapi tertawa dan tidak ada satupun responden $(0 \%)$ yang mengalami peningkatan tingkat kecemasan setelah diberikan terapi tertawa.

Hasil data tersebut menunjukkan perubahan tingkat kecemasan sebelum dan sesudah diberikan terapi tertawa pada lanjut usia di UPTD Griya Werdha Surabaya. Hal ini sesuai dengan teori yang dikemukakan oleh Ayu (2011), tertawa dapat memperlebar pembuluh darah dan mengirim lebih banyak darah hingga ke ujung-ujung dan semua otot di seluruh tubuh terutama ke otak, sehingga merangsang otak mengeluarkan hormon endorphine dan serotonin yaitu sejenis morfin alami tubuh dan juga melatonin yang membuat tubuh menjadi rileks.

Peneliti berpendapat terdapat penurunan tingkat kecemasan lansia sebelum dan sesudah diberikan terapi 
tertawa terjadi karena pertama keadaan psikis responden selama terapi dimana responden mengungkapkan bahwa responden merasa senang dengan terapi yang diberikan oleh peneliti dan menganggap ini hal yang baru sehingga responden menjadi senang dan antusias maka terapi dapat berjalan maksimal dan keadaan rileks bisa tercapai. Kedua adalah semakin lama lansia melakukan terapi maka akan semakin berkurang tingkat kecemasannya, bisa dikatakan bahwa tertawa merupakan meditasi dinamis atau teknik relaksasi yang dinamis dalam waktu singkat. Namun dari 33 responden ada 10 responden yang tidak mengalami penurunan kecemasan hal ini diduga faktor lingkungan yang mempengaruhi tidak adanya perubahan penurunan tingkat kecemasan. Maksud lingkungan disini yaitu responden tidak menyukai kondisi dimana responden tersebut harus berhubungan atau bersosialisasi dengan orang lain pada saat diberikan terapi. Hal ini sesuai dengan teori bahwa lingkungan merupakan salah satu penyebab perubahan mental pada lanjut usia, sehingga pada saat di stimulus atau diberikan terapi responden tersebut tidak dapat fokus dengan apa yang telah diberikan dan menyebabkan responden tersebut tidak merasa rileks saat diberikan terapi.

\section{KESIMPULAN}

Berdasarkan penelitian yang telah dilakukan, maka dapat disimpulkan sebagai berikut :

1. Lanjut usia di UPTD Griya Werdha Surabaya sebelum diberikan terapi tertawa sebagian besar mengalami kecemasan sedang.
2. Lanjut usia di UPTD Griya Werdha Surabaya sesudah diberikan terapi tertawa hampir seluruhnya mengalami kecemasan ringan.

3. Terapi tertawa berpengaruh terhadap tingkat kecemasan pada lanjut usia di UPTD Griya Werdha Surabaya.

\section{DAFTAR PUSTAKA}

Ayu, A. (2010). Terapi Tertawa untuk Hidup Lebih Sehat, Bahagia dan Ceria.Yogyakarta, Pustaka Larasati

Azizah, Lilik Ma'rifatul. (2011). Keperawatan Lanjut Usia. Edisi 1. Yogyakarta, Graha Ilmu

Halgin, R.P., Whitbourne, S.K. (2010). Psikologi Abnormal : Perspektif Klinis pada Gangguan Psikologi. Jakarta, Salemba Medika

Hawari, Dadang. (2013). Manajemen Stres, Cemas dan Depresi. Cetakan Keempat Edisi II. Jakarta, Fakultas Kedokteran Universitas Indonesia

Isaacs, Ann. (2005). Keperawatan Kesehatan Jiwa dan Psikiatri. Edisi 3. Jakarta, EGC

Kataria. (2004). Laugh For No Reason (Terapi Tertawa). Jakarta, PT. Gramedia Pustaka Utama

Katona, C., Cooper, C., Robertson, M. (2012). At a Glance Psikiatri Edisi Keempat. Jakarta, Erlangga

Manurung, Nixson. (2016). Terapi Reminiscence. Jakarta, TIM

Maryam, R. S. (2008). Mengenal Usia Lanjut dan Perawatannya. Jakarta, Salemba Medika

Nasir, Abdul \& Muhith, Abdul. (2011). Dasar-dasar Keperawatan Jiwa : Pengantar dan Teori. Jakarta, Salemba Medika 
Notoatmojo, Soekidjo. (2010). Metodelogi Penelitian Kesehatan Edisi Revisi Cetakan Pertama. Jakarta, Rineka Cipta

Nugroho, Wahyudi. (2008). Keperawatan Gerontik \& Getriatrik, Edisi 3. Jakarta, EGC

Nursalam. (2013). Konsep Penerapan Metode Penelitian Ilmu Keperawatan. Jakarta, Salemba Medika

Padila. (2013). Buku Ajar Keperawatan Gerontik. Yogyakarta, Nuha Medika

Potter, Patricia A \& Perry Anne G. (2005). Buku Ajar Fundamental Keperawatan. Edisi 4. Jakarta, EGC

Setyoadi, Kushariyadi. (2011). Terapi Modalitas Keperawatan Pada Klien Psikogeriatrik. Jakarta, Salemba Medika

Videbeck, Sheila L. (2011). Buku Ajar Keperawatan Jiwa. Jakarta, IKAPI 